\title{
Características de replicación y supervivencia del virus de viremia primaveral de la carpa (SVCV) aislado en México
}

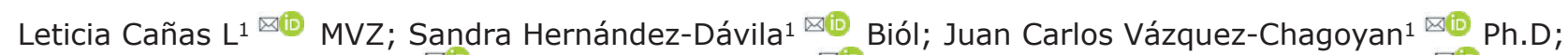

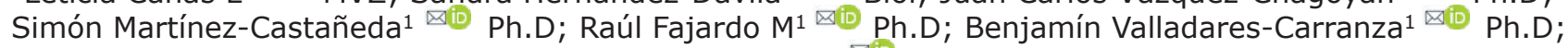
César Ortega $\mathrm{S}^{1 *} \otimes(\mathbb{D})$ Ph.D.

1Universidad Autónoma del Estado de México, Facultad de Medicina Veterinaria y Zootecnia, Centro de Investigación y Estudios Avanzados en Salud Animal (CIESA). Carretera Toluca-Atlacomulco Km. 15.5, CP 50200. Toluca, México.

Correspondencia: cortegas@uaemex.mx

Recibido:Diciembre 2019; Aceptado: Mayo 2020; Publicado: Agosto 2020.

\section{RESUMEN}

Objetivo. Realizar el aislamiento del virus de la viremia primaveral de la carpa (SVCV) en ejemplares de carpa común (Cyprinus carpio), evaluar su crecimiento en diferentes tipos de células, así como la supervivencia viral a diferentes temperaturas. Materiales y métodos. Diez carpas de entre 400500 gramos de una laguna del centro de México fueron procesadas para el diagnóstico de SVCV mediante aislamiento en cultivo de células y RT-PCR semianidado. El virus obtenido se inoculó en células EPC, BF-2, CHSE-214 y RTG-2 para determinar diferencias de crecimiento de SVCV. Además, se evaluó la supervivencia del virus conservado a temperatura ambiente (TA $20-25^{\circ} \mathrm{C}$ ), refrigeración (REF $4^{\circ} \mathrm{C}$ ) y congelación (CONG $-80^{\circ} \mathrm{C}$ ) hasta once meses. Los órganos internos se procesaron para análisis histológico. Resultados. Los peces analizados no presentaron signos externos sugestivos de enfermedad, pero interna e histopatológicamente se observaron lesiones sugestivas de infección sistémica. SVCV fue aislado en células EPC y BF-2 y confirmado por RT-PCR semianidado. SVCV únicamente indujo CPE en células EPC y BF-2 y fue negativo en RTG-2 y CHSE-214. El virus conservado a TA perdió viabilidad después de cuatro meses post infección ( $\mathrm{mpi}$ ), siendo total a seis mpi; mientras REF y CONG fueron estables durante los once meses de estudio. Conclusiones. La infección subclínica por SVCV fue confirmada en carpas que presentaron lesiones histológicas asociadas a esta infección. SVCV únicamente causó CPE en células EPC y BF-2 y el virus conservó su viabilidad a $4^{\circ} \mathrm{C} \mathrm{y}-80^{\circ} \mathrm{C}$ hasta once meses; mientras que a TA se perdió en seis meses.

Palabras clave: Cyprinus carpio; peces; enfermedad; RT-PCR; infección, células (Fuente: AGROVOC).

\section{ABSTRACT}

Objective. To perform the isolation of spring viremia of carp virus (SVCV) in common carp (Cyprinus carpio) and evaluate its growth in different cell types and viral survival at different temperatures. Materials and methods. Ten carps of between 400-500 grams of a lagoon in central Mexico were processed for diagnosis of SVCV by isolation in cell culture and by RT-PCR. The virus obtained was inoculated into EPC, BF-2, CHSE-214 and RTG-2 cells to determine differences in virus growth; the

Como citar (Vancouver).

Cañas LL, Hernández-Dávila S, Vázquez-Chagoyan JC, Martínez-Castañeda S, Fajardo MR, Valladares-Carranza B, Ortega SC. Características de replicación y supervivencia del virus de viremia primaveral de la carpa (SVCVV) aislado en México. Rev MVZ Córdoba. 2020; 25(3):e1875. https://doi.org/10.21897/rmvz.1875 
survival of virus stored at room temperature (TA $20-25^{\circ} \mathrm{C}$ ), refrigeration (REF $4^{\circ} \mathrm{C}$ ) and freezing (CONG $-80^{\circ} \mathrm{C}$ ) up to eleven months was also evaluated. Internal organ samples were processed for histological analysis. Results. The fish analyzed did not show external signs suggestive of disease but internally and histopathologically lesions suggestive of systemic infection were observed. SVCV was isolated in EPC and BF-2 cells and confirmed by semi-nested RT-PCR. SVCV only induced CPE in EPC and BF-2 cells and was negative in RTG-2 and CHSE-214. The virus conserved at TA lost viability after four months post-infection (mpi), being total at six mpi; while REF and CONG were stable during the eleven months. Conclusions. Subclinical SVCV infection was confirmed in carp that presented histological lesions associated with this infection; SVCV only caused CPE in EPC and $\mathrm{BF}-2$ cells; and the virus kept in refrigeration and at $-80^{\circ} \mathrm{C}$ retained its viability up to eleven months; while TA was lost in six months.

Keywords: Cyprinus carpio; fish; disease; RT-PCR; infection; cells (Source: AGROVOC).

\section{INTRODUCCION}

La viremia primaveral de la carpa (SVC) es una enfermedad sistémica infecciosa que afecta principalmente a ciprínidos; aparece inscrita en la lista de enfermedades de declaración obligatoria para la Oficina Internacional de Salud Animal (OIE), por considerarse uno de los principales riesgos económicos y sanitarios para carpas en condiciones de cultivo intensivo. En peces silvestres generalmente se presenta en forma subclínica, por lo que la infección puede pasar desapercibida $(1,2)$.

La SVC ocurre principalmente en peces menores a un año con tasas de mortalidad que pueden alcanzar el $90 \%$. La mortalidad y los signos clínicos están influenciados por diversos factores, entre los que destacan la edad de los peces, presencia de infecciones secundarias y la temperatura del agua ${ }^{2}$. La signología clínica más común ocurre a temperaturas entre 10 a $17^{\circ} \mathrm{C}$; en este rango de temperatura puede haber igual mortalidad acumulada, con mortalidad más rápida a los $17^{\circ} \mathrm{C}(1,2)$.

En la infección septicémica los peces muestran signos clínicos inespecíficos como palidez branquial, exoftalmia, hemorragias y petequias en piel, branquias y ojos, distención abdominal; a la necropsia se observa fluido seroso o mezclado con sangre o material necrótico, hemorragias focales o petequias en músculo y tejido adiposo, vejiga natatoria y otros órganos abdominales; bazo generalmente inflamado con textura gruesa (1). En casos crónicos se presentan adherencias pleurales y entre órganos internos; los animales que no mueren y los que se infectan sin padecer enfermedad clínica permanecen como portadores $(2,3)$.

La SVC se reportó por primera ocasión en 1970 en Yugoslavia (1), y se ha informado en países de Europa $(1,2)$, Oriente Medio (4) y China (2). En América se ha reportado en EE.UU $(2,3)$, Canadá y Brasil (2); y oficialmente no ha sido reconocida en México $(5,6)$.

SVCV ha sido replicado en cultivos primarios de gónadas y vejiga natatoria de carpa en varias líneas de células de peces e inclusive en líneas celulares de otros vertebrados $(1,2)$. Sin embargo, las células EPC (epithelioma papulosum cyprini) y FHM (fathead minnow) se consideran de elección $(1,2)$. Además, SVCV presenta diferencias de crecimiento y supervivencia ante diferentes condiciones de temperatura. De acuerdo al Manual de Diagnóstico de Organismos Acuáticos de la OIE (2), para el diagnóstico de SVCV debe aplicarse más de una técnica; en peces clínicamente afectados mediante aislamiento viral o a través de detección directa en tejidos por inmunofluorescencia indirecta (IFAT), ELISA o PCR; la identificación directa deberá confirmarse por el aislamiento más neutralización o por RT-PCR más la secuenciación del producto obtenido.

En la producción pesquera de México, por volumen las carpas (Cyprinus spp.) ocupan el $8^{\circ}$ lugar (53.421 ton) y por valor económico el lugar $14^{\circ}(7)$. Desde su ingreso a México, las carpas se distribuyeron en cuerpos de agua de casi todo el país y se destinan casi exclusivamente a la producción extensiva $(7,8,9)$. A nivel sanitario, son escasos los reportes de casos de enfermedad clínica y no existen estudios para determinar el estado sanitario en poblaciones de carpas mexicanas, basados en un diagnóstico sanitario integral (5).

A fines del año 2015, se reportó la presencia de SVCV en carpa común (Cyprinus carpio carpio) de una laguna del centro de México (5). Los peces analizados para el diagnóstico no presentaron signos de enfermedad, y se 
informó que no se habían presentado evidencias de enfermedad o mortalidad en la población de peces de la laguna de Tecocomulco. Tras la comunicación del aislamiento, las autoridades descartaron la presencia del virus mediante un análisis molecular, basado en RT-PCR. Por tanto, oficialmente SVCV se considera exótico para el país (6). En este trabajo se describen estudios que han permitido confirmar la presencia de SVCV en carpas de México mediante cultivo de células y RT-PCR semianidado, describiendo también las características de crecimiento del virus en diferentes tipos de células de cultivo y la supervivencia viral a diferentes temperaturas.

\section{MATERIAL Y MÉTODOS}

Obtención de muestras. Luego que las autoridades sanitarias descartaran mediante diagnóstico molecular la presencia del SVCV en el cuerpo de agua de donde se aisló el virus en octubre de 2015 (5), noventa días después se colecto una muestra adicional de 10 carpas comunes de entre 400-500 gramos, capturadas por pescadores de la laguna Tecocomulco para realizar un diagnóstico sanitario integral. Las muestras se obtuvieron durante el proceso de preparación de los peces para el consumo de visitantes a la laguna.

Aislamiento en cultivo de células. De cada pez se obtuvieron fragmentos de riñón de aproximadamente $0,5 \mathrm{~cm}^{3}$ los cuales se conservaron en pools de dos especímenes sumergidos en tubo Falcón de $15 \mathrm{~mL}$ conteniendo $9 \mathrm{~mL}$ de medio L-15 (Medium LEIBOVITZ'S Cat 11415-064, GIBCO BRL) suplementado a $2 \%$ de suero fetal bovino (SFB), y se conservaron a $4^{\circ} \mathrm{C}$. Antes de transcurrir 24 horas, el contenido de los tubos se maceró, centrifugó y se filtró con membranas de $0.22 \mu \mathrm{m}$. El filtrado en diluciones $1: 10$ y $1: 100$ se inoculó en monocapas de células EPC de $\geq 90 \%$ de confluencia; como control positivo se inocularon dos pocillos con $100 \mu \mathrm{L}$ de SVCV, y como control negativo dos pocillos con $100 \mu \mathrm{L}$ de medio $\mathrm{L}-15$ con $2 \%$ de SFB. Las placas se incubaron a $20^{\circ} \mathrm{C}$ y a $25^{\circ} \mathrm{C}$. La manifestación de efecto citopático (CPE) se registró al microscopio diariamente.

Replicación de SVCV en diferentes líneas celulares. El sobrenadante del aislamiento primario se cosechó y se realizaron diluciones $1: 10$ y $1: 100$, de las que $100 \mu \mathrm{L}$ se inocularon en monocapas de células EPC (epithelioma papulosum cyprini), BF-2 (Bluegill fry - Lepomis macrochirus), CHSE-214 (Chinook salmon embryo) y RTG-2 (rainbow trout gonad) y se incubaron a $20^{\circ} \mathrm{C}$ durante 7 días para determinar en cuáles células hubo multiplicación del virus.

Sobrevivencia de SVCV conservado a 3 diferentes temperaturas. El sobrenadante del cultivo del aislamiento primario se dividió en tres alícuotas. Una se conservó a temperatura ambiente (TA $20-25^{\circ} \mathrm{C}$ ), otra en refrigeración (REF $4^{\circ} \mathrm{C}$ ), y la última en congelación (CONG $-80^{\circ} \mathrm{C}$ ). La supervivencia del virus conservado durante un periodo de once meses (marzo 2016 a enero 2017) a diferente temperatura se obtuvo determinando la máxima dilución en la que el virus fue capaz de ocasionar CPE. El título se calculó mediante diluciones seriadas desde $10^{-1}$ a $10^{-8}$ en células EPC de $90 \%$ de confluencia en placa de 96 pocillos. La placa fue sellada e incubada a $25^{\circ} \mathrm{C}$ y se registró la presencia o ausencia de CPE hasta 7 días post-inoculación para determinar el título viral.

Histopatología. Muestras de bazo, hígado, riñón e intestino se fijaron en formalina buferizada a $10 \%$, deshidratados y embebidos en bloques de parafina mediante los procedimientos estándarizados. Cada tejido fue seccionado a $5 \mu \mathrm{m}$ y teñidos con Hematoxilina-Eosina para describir sus alteraciones histopatológicas bajo diferentes objetivos en un microscopio de luz Olympus $\mathrm{BH}-2$.

Extracción de RNA y RT-PCR para confirmación de SVCV. La presencia de SVCV en muestras con CPE se confirmó mediante RTPCR en cuatro de los cinco sobrenadantes. Para extraer ARN se utilizaron $200 \mu \mathrm{L}$ de sobrenadante de los cultivos con CPE siguiendo instrucciones del FavorPrep ${ }^{\mathrm{TM}}$ Viral Nucleic Acid Extraction Kit (Taiwan). El cDNA se sintetizó mediante transcripción inversa usando PrimeScript ${ }^{T M} \mathrm{RT}$ reagent Kit (Perfect Real Time, TAKARA, Japan) agregando $1 \mathrm{ng}$ de ARN total por cada reacción en un volumen total de $20 \mu \mathrm{l}$.

Se realizó un PCR semi-anidado (2), donde en el primer paso se usaron los oligos VVPC F1 5'-TCTTGGAGCCAAATAGCTCARRTC-3' y VVPC R2 5'-AGATGGTATGGACCCCAATACATHACNCAY-3' que amplifican 714 pares de bases $(\mathrm{pb})$ en reacción de $25 \mu \mathrm{L}$, donde también se adicionó GoTaq ${ }^{\circledR}$ Green Master Mix (Promega, USA) y 200 ng de cDNA. El producto de PCR obtenido se utilizó como templado en una segunda reacción que amplifica un producto de $606 \mathrm{pb}$ utilizando los oligos: VVPC F1 5'-TCTTGGAGCCAAATAGCTCARRTC-3' y 
SVCVR4: 5'-CTGGGGTTTCCNCCTCAAAGYTGY-3' en $25 \mu \mathrm{L}$ de reacción con concentraciones similares al PCR anterior. Los amplificados se revelaron mediante electroforesis en gel de agarosa a $1.5 \%$ peso/volumen.

Para descartar que las carpas fueran portadoras del virus de la necrosis pancreática infecciosa (IPNV), las células con CPE fueron sometidas a inmunofluorescencia indirecta (IFAT) y RT-PCR para IPNV según protocolos del Manual OIE (2).

\section{RESULTADOS}

Análisis clínico y examen macroscópico. Los peces revisados no presentaron signos ni lesiones externas asociadas a alguna enfermedad (Figura $1 \mathrm{~A})$. Además, los pescadores del lugar reportan que no han ocurrido situaciones de enfermedad o mortalidad en los peces de la laguna. Sin embargo, durante la necropsia, internamente se observó congestión moderada y adherencias entre órganos internos y con la pared abdominal (Figura 1B).

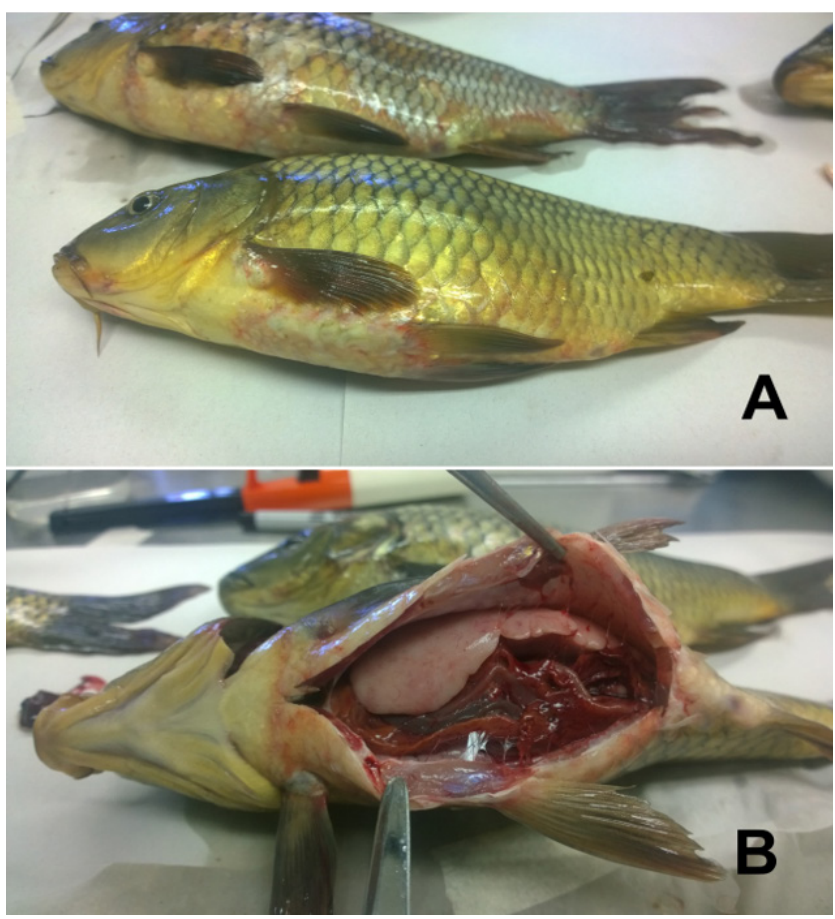

Figura 1. Carpas comunes con infección natural con SVCV. Superficie corporal externa sin lesiones aparentes (1A). A la necropsia se observaron adherencias entre órganos internos y entre órganos con pared abdominal (1B).

Aislamiento de SVCV. Las cuatro muestras inoculadas tanto en diluciones 1:10 y 1:100 en células EPC mostraron CPE. En las muestras incubadas a $25^{\circ} \mathrm{C}$, el CPE fue evidente en ambas diluciones desde 48 horas post-inoculación (hpi) (Figura 2B); mientras que, en las muestras incubadas a $20^{\circ} \mathrm{C}$, el CPE se presentó a 72 hpi (Figura 2C). En ambos casos, el CPE se caracterizó por formación de áreas con redondeo y desprendimiento de células, ruptura de la monocapa y lisis celular (Figura 2D).

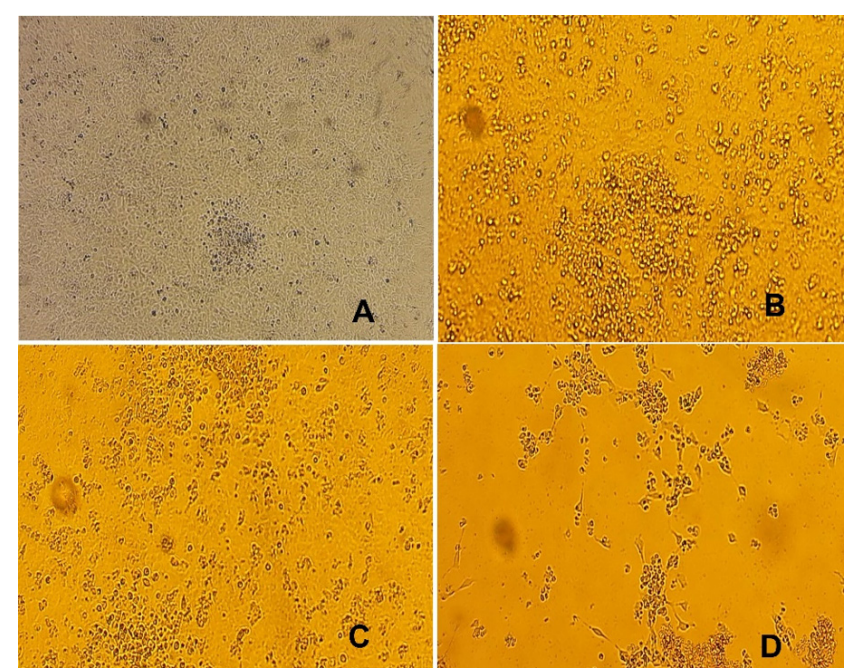

Figura 2. Células EPC infectadas con SVCV en dilución $1: 10$ e incubadas a $25^{\circ} \mathrm{C}$. Células sin infección $(A)$; células incubadas a $25^{\circ} \mathrm{C}$ con $\mathrm{CPE}$ a $48 \mathrm{hpi}(\mathrm{B})$, células incubadas a $20^{\circ} \mathrm{C}$ con $\mathrm{CPE}$ a 72 hpi (C); destrucción final de la monocapa de células (D).

Multiplicación de SVCV en células EPC, RTG2, BF-2 y CHSE-214. Tras realizar la infección en diferentes líneas celulares, SVCV únicamente indujo CPE en las células EPC y BF-2. El CPE ocurrió a las 48 hpi en células EPC, independiente de la dilución empleada; mientras que en BF-2 el CPE se manifestó a 72 hpi únicamente en la concentración $1: 10$. No se registró $\mathrm{CPE}$ en las líneas RTG-2 y CHSE-214 (Figura 3).

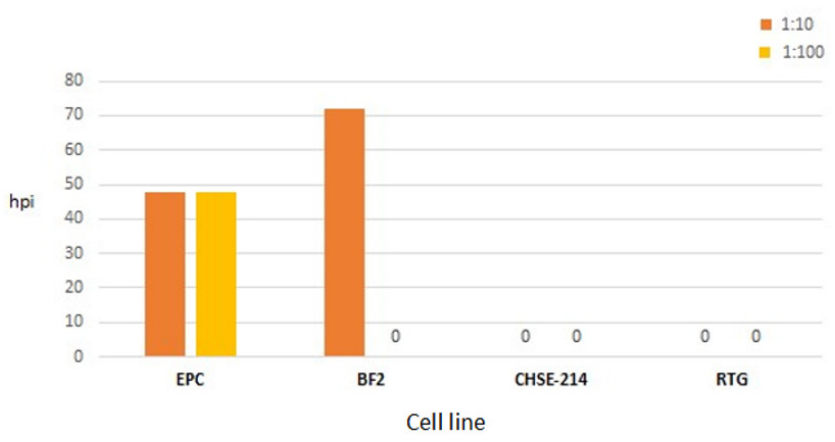

Figura 3. Manifestación de efecto citopático en células EPC, BF-2, CHSE-214 y RT-2 infectadas con SVCV en diluciones $1: 10 \mathrm{y}$ $1: 100$, incubadas a $20^{\circ} \mathrm{C}$. 
Sobrevivencia de SVCV conservado a 3 diferentes temperaturas. En la Figura 4, se muestra la supervivencia de SVCV mantenido a TA, REF y CONG. En general, el virus mantenido a TA tuvo menor supervivencia, en las primeras dos lecturas mostró CPE hasta la dilución -6 y posteriormente, en las inoculaciones de mayo y junio aumento a -7 , pero para las dos subsecuentes (de junio y julio), solo se observó CPE en la dilución -1, dejando de infectar en la inoculación de julio. Por su parte, el virus REF en las dos primeras fechas (marzo y abril) mostró CPE en dilución -7 , pero a partir de la lectura tres, aumentó a -8 y se mantuvo hasta el término del estudio. La alícuota CONG fue la más estable, desde la primera fecha de inoculación y hasta la número once causó CPE hasta la dilución -8.

Viral Titration Results

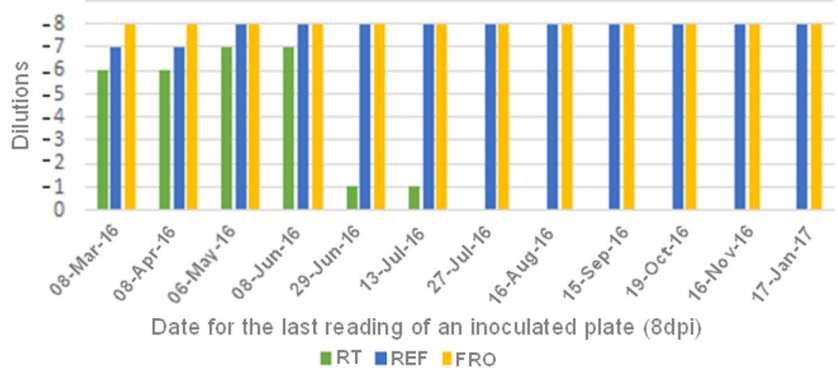

Figura 4. Títulos de virus obtenidos en tres alícuotas de SVCV conservados a temperatura ambiente (TA), en refrigeración (REF) y congelación (CON) durante once meses. El ensayo se realizo por inoculación en células EPC y titulación en microplaca (11).

Histopatología. Las principales lesiones histológicas se detectaron en riñón, observándose congestión sinusoidal y hemorragias intersticiales, proliferación de melano macrófagos, degeneración y necrosis tubular con vacuolización, hemorragia peritonal y esteatitis (Figura 5A). En hígado se detectó degeneración de paredes vasculares y necrosis hepática multifocal (Figura 5B), hemorragias perivasculares moderadas, pancreatitis e infiltraciones peri-pancreáticas (Figura 5C), hepatitis mononuclear multifocal (Figura 5D); enteritis ulcerativa granulomatosa (Figura 5E); degeneración esplénica, congestión, hemorragias y hemosiderosis esplénica y depleción linfoide (Figura 5F).
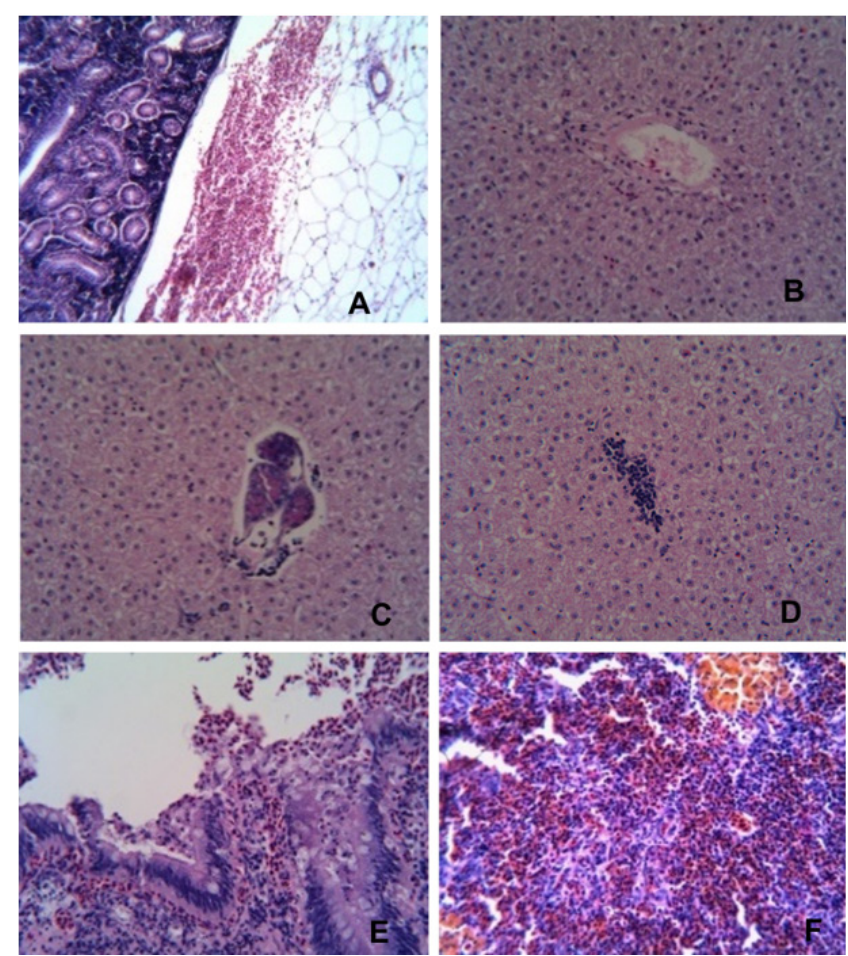

Figura 5. Lesiones histológicas en carpa común infectada por SVCV. Riñón: infiltración intersticial, hemorragia peritoneal y esteatitis, proliferación de melanomacrofagos 100x (A); Hígado: degeneración de paredes vasculares, degeneración y necrosis multifocal 250x (B); Peripancreatitis mononuclear y pancreatitis necrótica (C); infiltración linfocítica multifocal (D); Intestino: criptitis necrótica, enteritis hemorragica ulcerativa 250x (E); Bazo: congestión y hemosiderosis multifocal 250x (F)

Detección de SVCV mediante RT-PCR. El RT-PCR confirmó la presencia de SVCV en las cuatro muestras analizadas. De acuerdo con lo esperado en la primera reacción se obtuvo el producto de $716 \mathrm{pb}$, mientras que en la segunda reacción se amplificó el producto específico de $606 \mathrm{pb}$ (Figura 6).

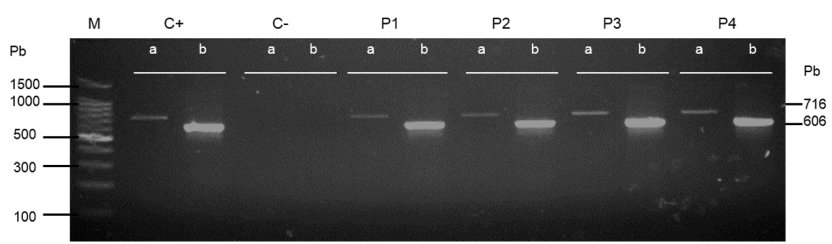

Figura 6. Detección de SVCV por RT-PCR semianidado utilizando el protocolo OIE. Línea M, indicador de peso molecular; $\mathrm{C}+$ control positivo, C- control negativo, P1, P2, P3 y P4 muestras de pools obtenidos de los peces analizados.

Los procesos de IFAT y RT-PCR para detección de IPNV resultaron negativos (No mostrado). 


\section{DISCUSIÓN}

El diagnóstico oportuno de SVC es una de las principales medidas para detectar y eliminar peces infectados y evitar exposición al virus $(1,2)$. En este sentido, la recomendación general para el diagnóstico de enfermedades infecciosas es obtener muestras de individuos que presenten signos clínicos y/o moribundos ya que en peces con infección subclínica el aislamiento puede ser difícil incluso en animales que han sobrevivido a brotes ocurridos con anterioridad $(1,3)$.

Los 10 peces empleados en este estudio no presentaron signos de enfermedad aunque si presentaron lesiones internas sugestivas de infección sistémica. Si bien las lesiones histopatológicas observadas no son específicas, son consistentes con aquellas descritas en casos de SVC, donde entre otras lesiones se describen daños vasculares en órganos internos que se traducen en hemorragias y formación de adherencias como las descritas en este caso $(2,3,10)$. Lo anterior se refuerza porque no se conoce de otra enfermedad viral que afecte a la carpa común en México $(5,6,10)$. Otros rhabdovirus como el de la septicemia hemorrágica (VHS) y de la necrosis hematopoyética infecciosa (IHN) que causan lesiones histológicas similares son exóticos para el país y tienen a la trucha arcoíris como hospedero $(1,2,11)$.

Tomando en consideración que los peces de la laguna no mostraron signos de enfermedad y que podrían ser portadores de SVCV, para tener mayor posibilidad de éxito en el aislamiento las muestras se inocularon en cuatro líneas de células, manifestándose CPE en las células EPC y BF-2 que son permisivas tanto para SVCV, como para IPNV, que es endémico en México $(6,11)$. La posibilidad de que el CPE observado se debiera al hecho que las carpas fueran portadoras de IPNV está descartado porque las muestras también se sometieron a RT-PCR e IFAT para IPNV con resultados negativos. Sin embargo, resultó positivo al RT-PCR semianidado para SVCV.

Aunque SVCV puede replicarse en células de peces y de otros animales $(2,12,13)$, no se conocen las razones de la permisividad y de los mecanismos de la interacción virus-célula $(12,14)$. En birnavirus se ha propuesto que utilizan receptores celulares comunes a distintas especies o bien receptores múltiples que se adhieren a las células, pero no garantizan la penetración en células no permisivas porque requieren de un correceptor que probablemente no presentan (16). En células CO (grass carp ovary) SVCV ingresa por endocitosis mediada por clatrina (CME) y macropinocitosis requiriendo participación de dinamina II, microfilamentos de actina, microtúbulos y acidificación endosomal (13). Sin embargo, es necesario determinar los elementos celulares que favorecen la permisividad de las células para permitir la endocitosis y la replicación $(12,13,15,16)$.

La manifestación clínica de SVC está asociada a varios factores siendo muy importante la temperatura $(1,2)$. En el ensayo para evaluar viabilidad a diferentes temperaturas en lapso de tres meses el virus mantenido a TA perdió drásticamente viabilidad e incluso desapareció a los seis meses. En este sentido, el virus permaneció viable hasta por cinco semanas en agua de río a $10^{\circ} \mathrm{C}$ o por más de seis en el barro de estanques a $4^{\circ} \mathrm{C}(2)$; evidenciando que cuando el virus permanece en contacto con materia orgánica se inactiva con mayor rapidez. Lo anterior podría ser una razón de que el virus no haya sido detectado tiempo después de cuando fue informado. La mayor supervivencia observada en este estudio en la muestra mantenida a temperatura ambiente podría explicarse por probable efecto protector del suero fetal bovino (SFB) incorporado en el medio de cultivo (2).

Continuando con lo anterior, el virus conservado en refrigeración y a $-80^{\circ} \mathrm{C}$ prácticamente conservó el mismo título durante los 11 meses. En este sentido, la literatura describe que el virus puede guardarse congelado a $-30 \mathrm{o}-74^{\circ} \mathrm{C}$ durante más de seis meses con poca pérdida de título si el medio contiene $2-5 \%$ de SFB $(1,2)$. Sin embargo, en el estudio no se evaluó el posible efecto del SFB.

El aislamiento puede ser difícil cuando la temperatura es distinta de aquella a la que se manifiesta la enfermedad clínica (2). Ahne, 1986 (17) informo $90 \%$ de mortalidad y altos títulos de virus en peces mantenidos en agua de entre 10 a $12^{\circ} \mathrm{C}$, mientras que entre 20 a $22^{\circ} \mathrm{C}$ no hubo mortalidad y no fue posible re-aislar al virus. La pérdida de títulos de virus debido al incremento de la temperatura podría ser una razón para que el laboratorio oficial no pudiera detectar al virus cuando acudió a colectar muestras en el mes de marzo, cuando la temperatura promedio del agua en la laguna es de $16,6^{\circ} \mathrm{C}$; en octubre, cuando se obtuvieron las muestras de este estudio la temperatura promedia $13.5^{\circ} \mathrm{C}(18)$. 
El tipo de muestra y las técnicas de diagnóstico utilizadas para la detección de agentes infecciosos son determinantes para obtener resultados confiables $(1,2,16,19)$. SVCV puede aislarse con cierta facilidad de peces clínicamente afectados en los cuales se ha detectado antígeno y/o ácido nucleico viral, y es menos probable lograr la detección directa de antígenos o ácidos nucleicos en tejidos de peces que sean portadores subclínicos. Sin embargo, el hecho de no encontrar el agente en estas muestras no garantiza ausencia en los animales analizados ni en la población $(1,2)$. En este estudio, el cultivo de células permitió lograr el aislamiento de SVCV y la confirmación subsecuente mediante RT-PCR, con lo cual el diagnóstico se ajustó a la recomendación OIE. Un resultado de PCR positivo requiere aislamiento para considerarse definitivo; pero está indicado para demostrar SVCV en cultivos celulares (2).

En este estudio se determinó que al utilizar cuatro líneas de células el virus solo causa CPE en células EPC y BF-2, y que en EPC el efecto se presenta más rápidamente; asimismo, el virus puede conservar su titulación incluso hasta por once meses si es que se conserva a temperatura de refrigeración y a $-80^{\circ} \mathrm{C}$. Si bien el virus ha sido plenamente identificado según recomendación de instancias sanitarias internacionales (2), y también ha sido molecularmente caracterizado (5), es necesario conocer los mecanismos moleculares o celulares que influyen en los resultados que aquí se obtuvieron.

\section{Conflicto de intereses}

Los autores de este estudio declaramos que no existe conflicto de intereses con la publicación del presente manuscrito

\section{Agradecimientos}

Los autores agradecen al Concejo Nacional de Ciencia y Tecnología Conacyt-México por el financiamiento al Proyecto de Investigación Ciencia Básica referencia 287537, con clave UAEM: 4489/2018.

\section{REFERENCIAS}

1. Ashraf $U$, Lu $Y$, Lin $L$, Yuan J, Wang $M$, Liu $X$. Spring viraemia of carp virus: recent advances. J Gen Virol. 2016; 97(5):1037-1051. https://doi.org/10.1099/ jgv. 0.000436

2. OIE. Spring viraemia of carp, Aquatic Animal Health Code. [en linea]. World Organization for Animal Health: Paris; 2019. [Acceso 18 Junio 2019]. URL disponible en: https: $/ /$ www.oie.int/en/standard-setting/aquaticcode/access-online/?htmfile = chapitre svc. $\underline{\text { htm }}$

3. Phelps N, Armién A, Mor S, Goyal S, Warg J, Bhagyam R, Monahan T. Spring Viremia of Carp Virus in Minnehaha Creek, Minnesota. J Aquat Anim Health; 2012; 24(4):232-237. https://doi.org/10.1080/08997659.2012.7 11267
4. Haghighi-Khiabanian AA, Bandehpour $M$, Sharifnia Z, Kazemi B. The first report of Spring Viraemia of carp in some rainbow trout propagation and breeding by pathology and molecular techniques in Iran. Asian J Anim Vet Adv. 2008; 3(4):263-268. https:// doi.org/10.3923/ajava.2008.263.268

5. Ortega C, Cañas-Lopez L, Irgang R, Fajardo $\mathrm{R}$, Poblete-Morales $M$, Valladares-Carranza $B$, et al. First detection of spring viraemia of carp virus in common carp (Cyprinus carpio L.) affected by a septicaemic disease in Mexico. J Fish Dis. 2019; 42(5):667-675. https://doi.org/10.1111/jfd.12969

6. Diario Oficial de la Federación de México. ACUERDO mediante el cual se dan a conocer en los Estados Unidos Mexicanos las enfermedades y plagas exóticas y endémicas de notificación obligatoria de los animales terrestres y acuáticos [internet]. México: Secretaria de Gobernación, 2018 noviembre [consultado 2019 junio 21]. 15 p. Disponible en https://dof.gob.mx/ nota detalle.php?codigo $=5545304 \&$ fec $\underline{\mathrm{ha}=29 / 11 / 2018}$ 
7. CONAPESCA. Anuario estadístico de acuicultura y pesca 2017. [internet]. México: Comisión Nacional de Acuicultura y Pesca, Secretaría de Agricultura Ganadería Desarrollo Rural Pesca y Alimentación. Diciembre 2017. [consultado 2019 junio 21]. 300 p. Disponible en https://www.conapesca. gob.mx/work/sites/cona/dgppe/2017/ ANUARIO ESTADISTICO 2017.pdf

8. FAO. Cultured aquatic species information programme. Cyprinus carpio (Linnaeus, 1758). [internet]. Rome: The Food and Agriculture Organization 2019. [consultado 2019 septiembre 27]. Disponible en http:// www.fao.org/fishery/culturedspecies/ Cyprinus carpio/en

9. Wakida-Kusunoki AT, Amador-del-Ángel LE. First record of the common carp Cyprinus carpio var. communis (Linnaeus, 1758) and the mirror carp Cyprinus carpio var. specularis (Lacepède, 1803) in Tabasco. Southern Gulf of Mexico. Aquat Invasions. 2011; 6(1):557-560. https://doi.org/10.3391/ ai.2011.6.51.013

10. Gaafar AY, Veselý T, Nakai T, El-Manakhly EM, Soliman MK, Soufy H, et al. Histopathological and ultrastructural study of experimental spring viraemia of carp (SVC) infection of common carp with comparison between different immunohistodignostic techniques efficacy. Life Sci. 2011; 8(3):523-533. http://www.lifesciencesite.com/Isj/life080 3/082 6932life0803 523 533.pdf

11. Ortega C, Valladares $B$, Arguedas D, Vega F, Montes de Oca R, Murray A. Distribution of Infectious Pancreatic Necrosis Virus (IPNV) Based on Surveillance Programs in Freshwater Trout Farms of Mexico. J Aquat Anim Health. 2016; 28(1):21-26. https:// doi.org/10.1080/08997659.2015.1131757

12. Liu H, Liu Y, Liu S, Pang DW, Xiao G. ClathrinMediated Endocytosis in Living Host Cells Visualized through Quantum Dot Labeling of Infectious Hematopoietic Necrosis Virus. J Virol. 2011; 83(13):6252-6262. https:// doi:10.1128/JVI.00109-11
13. Shao L, Zhao J, Zhang H. Spring viraemia of carp virus enters grass carp ovary cells via clathrin-mediated endocytosis and macropinocytosis. J Gen Virol. 2016; 97(11):2824-2836. https://doi:10.1099/ jgv.0.000595

14. Yuan J, Yang Y, Nie H, Li L, Gu W, Lin L, Zou M, Liu X, Wang M, Gu Z. Transcriptome analysis of epithelioma papulosum cyprini cells after SVCV infection. BMC Genomics. 2014; 15(935):1-15. http://www.biomedcentral. com/1471-2164/15/935

15. Imajoh M, Yagyu K, Oshima S. Early interaction of marine birnavirus infection in several cell lines. J Gen Virol. 2003; 84(7):1809-1816. https://doi.org/10.1099/ vir. $0.18869-0$

16. Lorenzen E, Carstensen B, Olesen NJ. Inter-laboratory comparison of cell lines for susceptibility to three viruses: VHSV, IHNV and IPNV. Dis Aquat Org. 1999; 37(2):8188. https://doi:10.3354/dao037081

17. Ahne $W$. The influence of environmental temperatura and infection route on the immune response of carp (Cyprinus carpio) to spring viremia of carp virus. Vet Immunol Immunopathol. 1986; 12(4):383-386. https://doi:10.1016/0165-2427(86)90144$\underline{3}$

18. Delgadillo A. Determinación de parámetros fisicoquímicos, estado eutrófico y metales pesados de la laguna de Tecocomulco, Hidalgo; identificación de compuestos quelantes de Hydrocotyle ranunculoides [Dissertation]. México: Universidad Autónoma del Estado de Hidalgo; 2012. [citado 2019 mayo 27]. Disponible en: http:// dgsa.uaeh.edu.mx:8080/bibliotecadigital/ handle/231104/1900

19. Matvienko N, Rud Y, Buchatsky L. Replication of infectious Pancreatic Necrosis Virus in different cell lines and in rainbow trout (Oncorhynchus mykiss) fingerlings. Arch Pol Fish. 2014; 22(6):127-133. https:// doi: $10.2478 / a o p f-2014-0012$ 